\title{
Structure and Gas Transport Behavior of Polysulfone/ Polyacrylonitrile-carbon Molecular Sieve Mixed Matrix Membrane
}

\author{
W. A.W. Rafidah ${ }^{1}$, A. F. Ismail ${ }^{2 *}$, T. Matsuura ${ }^{3}$, S. A. Hashemifard ${ }^{4}$ \& A. Suhaimi ${ }^{5}$ \\ ${ }^{1-4}$ Advanced Membrane Technology Research Centre (AMTEC), Universiti Teknologi Malaysia, \\ 81310 UTM Johor Bahru
}

\begin{abstract}
Mixed matrix membrane (MMM) comprising of polyacrylonitrile based carbon molecular sieve (PAN-CMS) and polysulfone (PSF) Udel ${ }^{\Phi} \mathrm{P}-1700$ were synthesized and characterized as an alternative material for gas separation. The structure and the gas transport behavior of this hybrid system was investigated by thorough analysis using thermal gravimetry analysis (TGA), differential scanning calorimetry (DSC), field emission scanning microscopy (FESEM) and single gas permeation test. The thermal analysis based on TGA and DSC results indicated that $T_{\mathrm{g}} \mathrm{s}$ and $\mathrm{T}_{d} \mathrm{~s}$ of PSF have been extended to higher temperatures. These findings suggest that PAN-CMS have improved the thermal property of PSF in the MMM system. FESEM micrographs revealed that the PSF/ PANCMS MMMs possess an acceptable PSF and PAN-CMS interfacial adhesion with the average interfacial gap size of less than 1ìm. The excellent gas separation capability of the PSF/ PAN-CMS MMM was proven as the hybrid film with 20 wt $\%$ PAN-CMS loading exhibited higher $\mathrm{O}_{2} / \mathrm{N}_{2}$ selectivity (5.80) than that of pure PSF film $(5.45)$.
\end{abstract}

Keywords: CMS, gas separation, mixed matrix membrane, polyacrylonitrile, polysulfone

\subsection{INTRODUCTION}

In recent years, the idea of utilizing polyacrylonitrile (PAN) polymer as an option for carbon precursor in gas separation membrane production has triggered a growing interest in this area of research. PAN fibers have been widely recognized as the most promising precursor for producing high performance carbon fiber. In fact, it dominates almost $90 \%$ of the worldwide sales of carbon fiber [1]. The utilization of PAN as carbon precursor has been extended to carbon molecular sieve membranes (CMSs) development in order to obtain numerous advantages such as high degree of molecular orientation, higher melting point, $T_{m}$ of $317-330^{\circ} \mathrm{C}$ and greater

\footnotetext{
* Corresponding to: A. F. Ismail (email: afauzi@utm.my)
}

yield of carbon [2]. PAN precursor forms a thermally stable, highly oriented molecular structure once being subjected to a low temperature heat treatment. This stabilized structure is not significantly disrupted during carbonization treatment or pyrolysis at higher temperature. As a result, the carbon membranes produced have better mechanical properties [3].

Attempts at fabricating PAN-based carbon for gas separation process have been initiated since 1990 by Schindler and Maier [4]. They had fabricated the porous capillary carbon membrane by conducting pyrolysis process up to $1600^{\circ} \mathrm{C}$ in inert gas environment. This effort has been carried on by several other researchers. Within 1994 to 1995, Linkov and his co-worker had made many contributions towards the development of PANbased carbon membranes by conducting intensive 
study concerning on the use of PAN precursor. Various approaches and modifications have been implemented in order to improve the gas separation properties of PAN-based carbon. They fabricated PAN-based carbon hollow fiber membranes by blending with methylmethacrylate [5], polyethylene glycol (PEG) and polyvinylpyrrolidone (PVP) [6] in order to modify the final pore size distribution of the carbon membranes. Besides, they also developed composite membranes using PAN based carbon membrane with zeolite [7], polyimide [8] and perfluoro-sulfonated ionomer (PSI) [9]. However the development of PAN based carbon membrane became slower in the following years until David and Ismail fabricated their carbon hollow fiber membrane from PAN precursor in late 2002 [10]. Subsequent research on carbon membrane production using PAN precursor has been extended by Saufi in 2004 who developed carbon hollow fiber membranes for $\mathrm{O}_{2} / \mathrm{N}_{2}$ gas separation [11]. Table 1 summarizes several important researches on PAN-based carbon membrane.

Forming continuous and defect-free carbon membranes is a very demanding procedure [12]. The development of PAN-based carbon membrane also faces with these challenges. Saufi [11] reported that extreme brittleness and the existence of cracks or defects were two critical issues confronting the effective use of his PANbased carbon molecular sieve (CMS) hollow fiber membrane for gas separation. In addition, this kind of handling issues limit the cost-effective use of molecular sieve membranes. Brittleness restrains the fabrication of membranes in module forms and increases the replacement costs. Therefore, hybridization approach or mixed matrix membrane is the most appropriate way to fully utilize the functionality of the PAN-based carbon. Hybrid of inorganic aggregates in a polymer binder is the latest emerging technique in gas separation membrane. It was well reported [15-21] that this approach is viable to synergistically combine the good features of both phases and simultaneously compensate the weaknesses in each medium. The high selectivity benefit of the carbon membrane is combined with the desirable mechanical properties and economical processabilities of polymers. The successful fabrication of carbon-polymer hybrids and their significant contribution in improving selectivity for several gas pairs have been demonstrated in $[17,22,23]$. This paper highlights the potential of PAN-based carbon for gas separation in MMM comprising of polyacrylonitrile (PAN)-based CMSs and polysulfone (PSF) Udel ${ }^{\circledR}$ P-1700. The synthesized MMM films were characterized and analyzed in order to examine the actual structure and to understand the gas transport behavior of this hybrid system.

Table 1 Previous researches on the fabrication of PAN-based carbon membrane

\begin{tabular}{|c|c|c|c|}
\hline Year & Configuration & Modification & References \\
\hline 1990 & Capillary & - & [4] \\
\hline 1990 & Hollow fibre & - & [12] \\
\hline 1992 & Hollow fibre & - & {$[13]$} \\
\hline 1994 & Hollow fibre & Using PAN/ methylmethacrylate blending precursor & {$[5]$} \\
\hline 1994 & Hollow fibre & Using PAN/ PEG blending precursor & {$[6]$} \\
\hline 1994 & Hollow fibre & Using PAN/ PVP blending precursor & {$[6]$} \\
\hline 1994 & Hollow fibre & Composite of PAN and PI & [8] \\
\hline 1995 & Hollow fibre & Composite of PAN and PSI & [9] \\
\hline 1995 & Hollow fibre & Comosite of PAN and Zeolite & {$[7]$} \\
\hline 2003 & Hollow fibre & - & {$[10]$} \\
\hline 2004 & Hollow fibre & - & [11] \\
\hline
\end{tabular}




\subsection{EXPERIMENTAL}

\subsection{Raw Material}

A commercial Udel ${ }^{\circledR}$ P-1700 polysulfone, purchased from Amoco Performance Inc., USA was chosen as the binding polymer. It has an average molecular weight of 45000 . The solvent, n-methyl-2-pyrrolidone (NMP) supplied by Merck was used as received. PAN-CMSs were synthesized by pyrolysis of polyacrilonitrile (PAN) precursor as described elsewhere [11]. The particle size of PAN-CMSs was reduced to less than $25 \mu \mathrm{m}$ as verified by FESEM. Prior to any use, PSF and PAN-CMSs were preconditioned in a vacuum oven at $100^{\circ} \mathrm{C}$ and $250^{\circ} \mathrm{C}$, respectively, for 12 hours to remove trapped moisture.

\subsection{Fabrication of Membrane Films}

Pre-dried PSF pellets were dissolved in NMP and stirred for 12 hours at the temperature of $60-70$ ${ }^{\circ} \mathrm{C}$ to form $20 \mathrm{wt} \%$ PSF in NMP solution. The PAN-CMS suspension was prepared by introducing the intended amount of PAN-CMSs into the PSF solution. Casting was performed by using a pneumatically controlled casting machine. The nascent membranes were immediately kept in preheated vacuum oven for 1 hour. For more effective removal of solvent without boiling it, the temperature in the oven was increased to $150^{\circ} \mathrm{C}$ under $\mathrm{N}_{2}$ purging and partial vacuum was applied to pump out the condensed solvent. The membranes were further dried up to $250{ }^{\circ} \mathrm{C}$ to remove solvent residual. The final membrane films were $30-40 \mu \mathrm{m}$ in thickness and were kept in vacuum oven at $60^{\circ} \mathrm{C}$ prior to characterization to avoid contamination by moisture or impurities.

\subsection{Polymer and Characterization}

The thermal poperties of polymer and membrane films were analyzed by means of Thermogravimetry analysis (TGA) and Differential Scanning Calorimetry (DSC). Analysis using Mettler Toledo thermogravimetry analyzer (TGA TSO800GC1) was performed in order to determine the decomposition pattern and decomposition temperature $\left(\mathrm{T}_{\mathrm{d}}\right)$ for polymer films. The sample was heated from $30^{\circ} \mathrm{C}-800^{\circ} \mathrm{C}$ with a heating rate of $10^{\circ} \mathrm{C} / \mathrm{min}$ under $\mathrm{N}_{2}$ atmosphere. $\mathrm{T}_{\mathrm{c}}$ of the sample was determined based on the TGA curve.

The glass transition temperature $\left(\mathrm{T}_{\mathrm{g}}\right)$ of the polymers was analyzed with differential scanning calorimetry (METTLER TOLEDO DSC 822e). Sample was cut into small pieces, weighed and placed into pre-weighed aluminum crucible. Then, the sample was heated from $30^{\circ} \mathrm{C}$ to $300{ }^{\circ} \mathrm{C}$ with a heating rate of $10^{\circ} \mathrm{C} / \mathrm{min}$ in the first cycle to remove the thermal history. The sample was cooled from $250{ }^{\circ} \mathrm{C}$ to $30^{\circ} \mathrm{C}$ at the rate of $10^{\circ} \mathrm{C} / \mathrm{min}$. The same heating procedure was repeated in the second heating cycle. $\mathrm{T}_{\mathrm{g}}$ of the sample was determined as the midpoint temperature of the transition region in the second heating cycle.

The cross-sectional structure of MMM films was diagnosed using a field emission scanning electron microscope (FESEM). Prior to testing, the film samples were fractured in liquid nitrogen in order to achieve a clean break. The samples were then mounted on a stainless steel stand with carbon tape and coated with $15 \mathrm{~nm}$ of gold using a sputter coater.

Gas permeation properties for membranes were determined using variable-volume constantpressure method with a permeation cell described elsewhere [24]. Each pure gas (99.97\% purity) was tested in the sequence of $\mathrm{N}_{2}$ and $\mathrm{O}_{2}$ and the permeation rate measured three times for each membrane. The measurement was performed at $30^{\circ} \mathrm{C}$ at 1.5 bar gauge. The pure gas permeability was determined using the following formula;

$P_{i}=\frac{V_{i} l}{A t \Delta p}$

Where $i$ represents the gas penetrant $i, V_{i}$ is the volume of gas permeated through the membrane in $\left(\mathrm{cm}^{3}, \mathrm{STP}\right), l$ is the membrane thickness in $\mathrm{cm}, A$ is the effective membrane area in $\mathrm{cm}^{2}, t$ is the permeation time in $s$ and $\Delta p$ is the transmembrane pressure drop in $\mathrm{cmHg}$. The selectivity was obtained using equation 3.0.

$\alpha_{i / j}=\frac{P_{i}}{P_{j}}$ 
Where $\alpha_{i / j}$ is the selectivity of gas penetrant $i$ to gas penetrant $j, P_{i}$ and $P_{j}$ are the permeability of gas penetrant $i$ and $j$ respectively.

\subsection{RESULTS}

Polysulfone films containing PAN-CMS with loading of $10-35 \mathrm{wt} \%$ were fabricated. Incorporation of PAN-CMSs at loading of more than $35 \mathrm{wt} \%$ resulted in fragile and brittle film.

\subsection{Thermal Analysis}

Thermal analysis of PSF- PAN based carbon films was performed by using Thermal Gravimetric Analysis (TGA) and Differential Scanning Calorimetry (DSC). The thermal property changes of PSF before and after mixing with PAN-CMSs were monitored by determining the decomposition temperature, $T_{d}$ and glass transition temperature, $T_{g}$ of pure PSF film and PSF films containing various loadings PANCMSs. The thermal analysis results for the pure PSF and the PSF/PAN-CMS MMM films are shown in Figure 1 and Table 2. The $T_{g}$ s for PSF/ PAN-CMS MMM films were approximately 2 . $3 \%$ higher than that of the pure PSF film. The shift in $\mathrm{T}_{\mathrm{g}}$ indicated that PAN-CMSs promoted the polymer amorphous structure to shift to higher extent of crystalline structure. In addition, the changes in $T_{g}$ due to the presence of the dispersed constituent also designated the changes in the mechanical properties of the polymer binder [25].

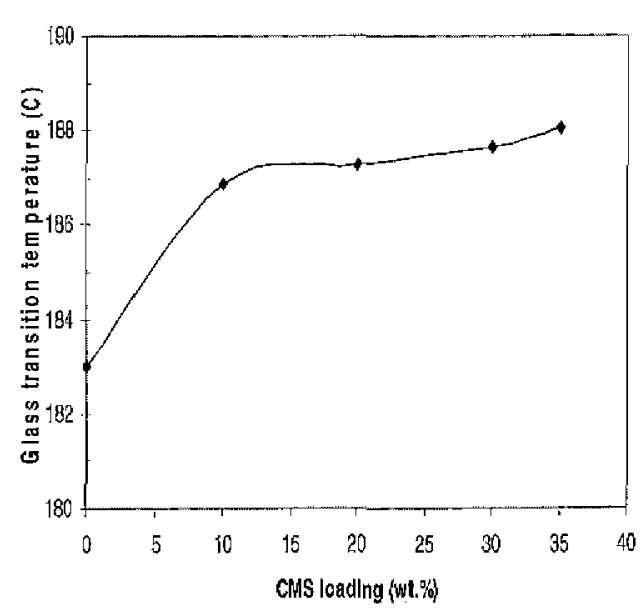

Figure 1 The glass transition temperature for PSF/PAN-CMS MMMs with various PAN-CMS loadings

Upon carbon addition, the fabricated film became more brittle and opaque compared to the pure PSF tilm. When the loading of PAN-CMSs was increased, the resultant film became extremely brittle and fragile. In agreement with Mahajan [22] and Li et al. [19-21], the increment in $\mathrm{T}_{\mathrm{g}}$ was possibly attributed to the restriction of polymer chain movement or rotation near the polymerfiller interphase. The PAN-CMSs dispersed in the continuous phase of PSF inhibit the isotropic contraction of the polymer and thus creating a rigid polymer region surrounding the PAN-CMSs. The $T_{g}$ shift phenomenon was also observed in other hybrid systems such as Matrimid ${ }^{\circledast}$-CMS, Ultem $^{\circledast}$ - CMS [17], PVA-zeolite [26], PES-zeolite [20]. Referring to Figure 2, it can be clearly seen

Table 2 Thermal properties of pure PSF and PSF/PAN-CMS MMMs at various PAN-CMS loading

\begin{tabular}{|c|c|c|c|c|}
\hline \multirow[t]{2}{*}{ Film sample } & \multirow{2}{*}{$\begin{array}{l}\text { PAN based } \mathrm{C} \\
\text { loading }(w t \%)\end{array}$} & \multirow{2}{*}{$\mathrm{T}_{\mathrm{g}}\left({ }^{\circ} \mathrm{C}\right)$} & \multicolumn{2}{|c|}{ Decompose Temperature, $\mathbf{T}_{\mathrm{d}}\left({ }^{\circ} \mathrm{C}\right)$} \\
\hline & & & Start & End \\
\hline PSF & 0 & 183.01 & 495.58 & 569.12 \\
\hline PSF-PBC10 & 10 & 186.86 & 505.84 & 554.87 \\
\hline PSF-PBC20 & 20 & 187.26 & 511.36 & 556.47 \\
\hline PSF-PBC30 & 30 & 187.66 & 511.53 & 557.28 \\
\hline PSF-PBC 35 & 35 & 188.04 & 516.10 & 549.92 \\
\hline
\end{tabular}




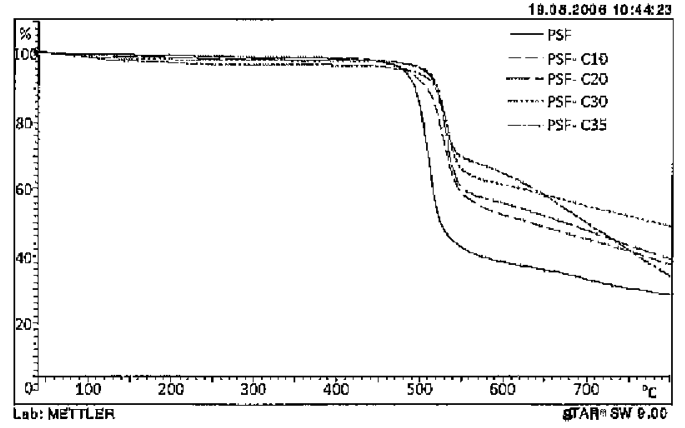

Figure 2 TGA thermogram of PSF/PAN-CMS MMMs with various PAN-CMS loadings

that the decomposition patterns were similar for all systems whereby the initial decomposition at around $490^{\circ} \mathrm{C}-520^{\circ} \mathrm{C}$ was attributed to decomposition of the main degraded constituent, PSF. The decomposition temperatures of PSF in hybrid films were extended to $2-4 \%$ higher than that of pure PSF. The higher the loading of PANCMSs, the higher the decomposition temperature of the film would be. The increase in $\mathrm{T}_{\mathrm{i}}$ denoted that the thermal stability of PSF was improved with the addition of PAN-CMSs. The initial weight loss of PSF-C35 around $100-120^{\circ} \mathrm{C}$ was probably caused by the removal of adsorbed water because it is known that water vapor can easily 'chemisorb' onto the carbon surface [27]. The percentage of weight loss between $490-560^{\circ} \mathrm{C}$ was attributed to the degradation of PSF matrix. Therefore, as the volume fraction of PAN-CMSs in the film increased, the amount of degradable PSF decreased giving a lower weight loss percentage.

\subsection{FESEM}

The cross-sectional morphologies of the PSF film containing various loadings of PAN-CMSs were explored using a field emission scanning electron microscope (FESEM). Figures 3 (a) - (e) show the representative FESEM images of the crosssection for pure PSF and PSF/PAN-CMS MMMs. Pure PSF film has an a dense structure across the entire membrane cross-section. The PAN-CMSs distorted the structure of the continuous PSF matrix and randomly distributed within the PSF matrix. The number of observable PAN-CMSs

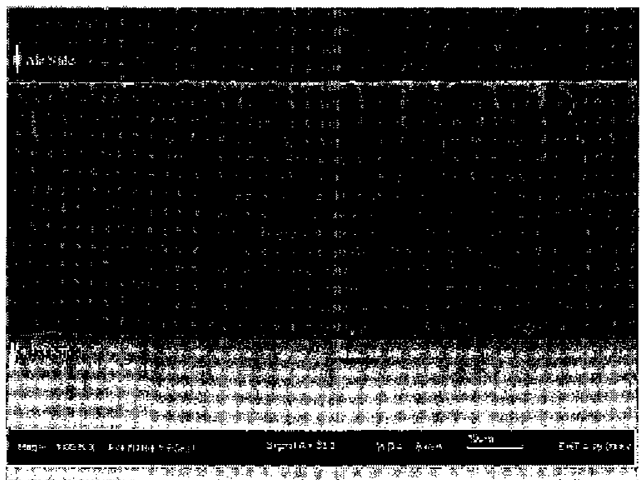

(a)

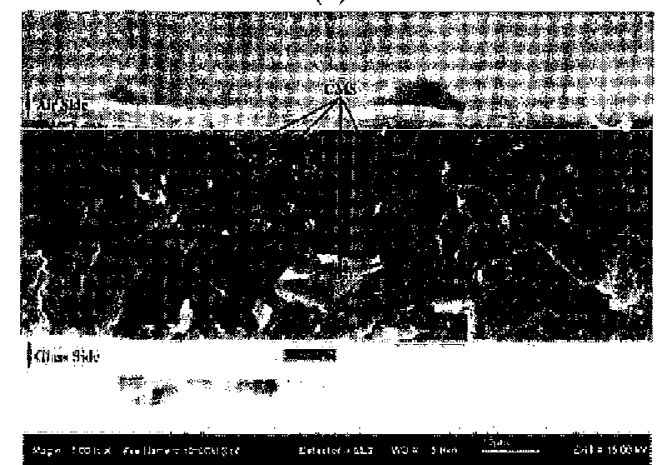

(b)

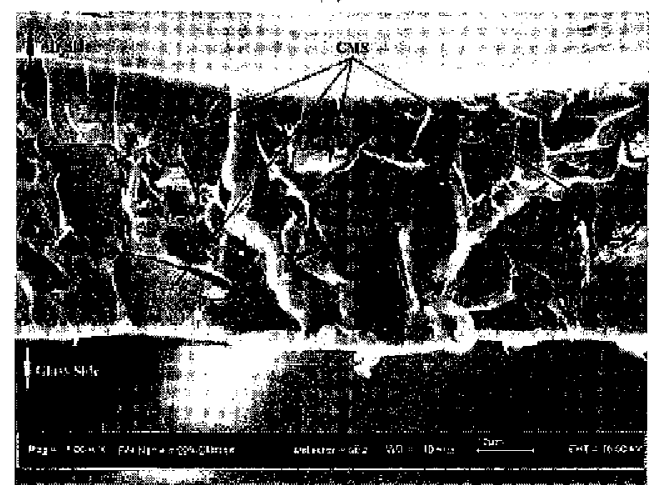

(c)

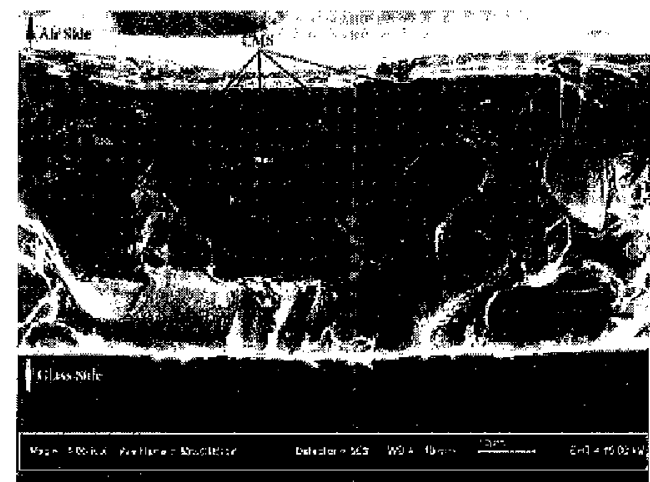

(d) 


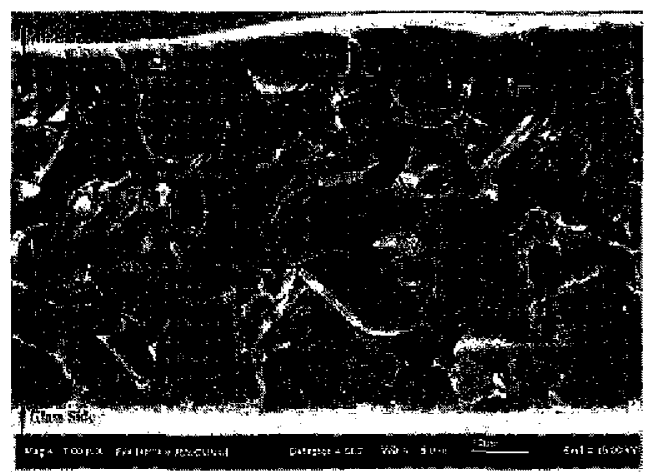

(e)

Figure 3 FESEM micrographs of the cross-section of(a) pure polysulfone membrane and PSF/PAN-CMS MMM with (b) $10 \mathrm{wt} \%$ (c) $20 \mathrm{wt} \%$ (d) $30 \mathrm{wt} \%$ and (e) $35 \%$ PAN-CMS loading under 1000 times magnification

increased with the increasing PAN-CMSs loading. As the carbon loading in PSF film was further increased to a higher loading ( $30-35 \mathrm{wt} \%$ ), the occurrence of sedimentation and clustering of PAN-CMSs were easily distinguished. Incleed, this kind of contact is undesirable to avoid nonselective channels across the MMM films [28]. On the other hand, the voids created within these agglomerates could affect the gas separation performance of membrane by providing alternate path for gas flow. This problem was widely reported by various researchers dealing with inorganic-polymer membranes $[16,17,22,28,29]$. In the present case, the sedimentation of larger size PAN-CMSs probably caused during the preparation process. Due to the difference of densities between NMP solvent $\left(\rho=1.03 \mathrm{~g} / \mathrm{cm}^{3}\right)$ and carbon $(1.48 \mathrm{~g} /$ $\left.\mathrm{cm}^{3}\right)$, most likely gravitational effects caused the PAN-CMSs to settle on the glass side of the membrane. Pechar et al. [30] have made the same conclusion.

In terms of interphase adhesion, the PANCMSs were not that intimately adhered to the PSF binding polymer. Interestingly, apparent existence of gap size of less than $1 \mu$ that bound the PANCMSs became significant in higher carbon loading film. Improper wetting of carbon with PSF binder was a probable cause for the creation of this nonideal effect. Increment in the volume fraction of carbon in PSF followed by sedimentation and clustering of PAN-CMSs inhibits the polymer chains to adequately reach the sieve surface. This was supported by [29]. Subsequently, partial incompatibility as a response to the polymer-sieve interactions within the hybrid network and stress generation during vitrification stage are other two possible reasons that could lead to polymer dewetting from carbon surface. Although some findings supported that PSP and carbon have favourable interactions compared to other fillers lilke zeolites $[16,17]$, these interactions might be too weals to tightly hold the sieve and to resist debonding forces. Although PSF is an intermediate $\mathrm{T}_{\mathrm{g}}$ polymer and the membranes were formed at the temperature close to the $\mathrm{T}_{\mathrm{g}}$ of PSF, it was likely that PSF has experienced a slight stress during vitrification process. The polymer chains shrunk and delaminated from the sieve surface during vitrification process. The phenomenon was reported by several researchers such as Mahajan [22], and Moore and Koros [31]. Overall, PSF/PAN-CMS MMMs possess moderate PSF and carbon interfacial adhesion with the average interfacial gap size of less than $1 \mu$ even at high carbon loading. A better adhesion would be expected by modifying the carbon surface prior to embedment into PSF polymer.

\subsection{Permeability Measurement}

In this study, the gas permeation properties of the fabricated membrane films were determined using single gas permeation test. The test was conducted at room temperature $\left(\mathrm{T}=30^{\circ} \mathrm{C}\right)$ and at the feed pressure of 1.5 bar. The gas permeation results for pure PSF membrane and PSF/PAN-CMS MMM s are summarized in Table 3 . The variation in the permeability values of $\mathrm{O}_{2}$ and $\mathrm{N}_{2}$ in PSF/ PAN-CMS MMM with respect to the carbon loading are depicted in Figure 4 and Figure 5 respectively. Generally the PSF/PAN-CMS MMMs exhibited higher $\mathrm{O}_{2}$ and $\mathrm{N}_{2}$ permeabilities compared to that of pure PSF. Plain PSF film exhibited the $\mathrm{O}_{2}$ permeability of 1.58 barrers and $\mathrm{N}_{2}$ permeability of 0.29 barrers. The $\mathrm{O}_{2}$ and $\mathrm{N}_{2}$ permeability for PSF/PAN-CMS MMMs were exponentially increased with respect to the carbon loading. The highest $\mathrm{O}_{2}$ and $\mathrm{N}_{2}$ 
Table 3 Gas permeation properties of pure PSF membrane and PSF/PAN-CMS MMMs

\begin{tabular}{lllll}
\hline Film sample & $\begin{array}{l}\text { PAN based C } \\
\text { loading (wt } \%)\end{array}$ & $\begin{array}{l}\mathbf{O}_{2} \\
\text { (barrers) }\end{array}$ & $\begin{array}{l}\mathbf{N}_{\mathbf{2}} \\
\text { (barrers) }\end{array}$ & $\mathbf{O}_{2} / \mathbf{N}_{2}$ \\
\hline & & & & \\
PSF & 0 & 1.58 & 0.29 & 5.45 \\
PSF-PBC10 & 10 & 4.00 & 0.69 & 5.80 \\
PSF-PBC20 & 20 & 7.60 & 1.33 & 5.71 \\
PSF-PBC30 & 30 & 12.51 & 3.25 & 3.85 \\
PSF-PBC35 & 35 & 17.03 & 5.99 & 2.84 \\
\hline
\end{tabular}

permeability was observed to be 17.03 barrers and 5.99 barrers respectively performed by MMM with $35 \mathrm{wt} \%$ carbon loading. On the other hand, the $\mathrm{O}_{2} / \mathrm{N}_{2}$ selectivity was enhanced with the addition of PAN-CMSs from 5.45 in pure PSF to the maximum value of $5.80 \mathrm{up}$ to $20 \mathrm{wt} \%$ carbon loading. The selectivity value drastically dropped with further increment in carbon loading. The lowest selectivity was also observed in MMM with $35 \mathrm{wt} \%$ carbon loading. The trend observed can be attributed to the relationship between membrane structure and gas permeability as being widely discussed in many inorganic-polymer hybrid systems [28].

\subsection{Effect of Membrane Structure on Gas Permeation in PSF/PAN CMS MMM Films}

According to Kiyono et al. [28], the gas transport behavior in inorganic-polymer materials are strongly related to the actual structure within the material itself. Supported by the FESEM micrographs presented in Figure 3 (a) - (e), the gas penetrants were likely to be transported through three primary media.

(i) Through PSF polymer which provided a selective but highly resistive to gas flow channel

(ii) Through porous PAN-CMSs which provided high selective channel with relatively lower resistance than that in PSF

(iii) Through interfacial gap between polymer and carbon interphase which provided non-selective and non-resistive to gas flow channel.
Generally the PSF/PAN-CMS MMMs exhibited higher $\mathrm{O}_{2}$ and $\mathrm{N}_{2}$ permeabilities compared to that of pure PSF membrane. As well, the dense structure of the pure PSF membrane made its permeation rate lower than that of the MMM of a comparable thickness. According to the FESEM analysis (Figure 3), at lower loadings an ideal morphology was experienced, which led to an enhancement in both permeability and selectivity. Because of this, for MMM with 10 wt $\%$ carbon loading, a slight increase in $\mathrm{O}_{2}$ permeability with no noticeable improvement in selectivity implies a relatively high contribution of gas transport through the PSF polymer. As previously shown in Figure 3 (b), despite exhibiting an intimate adhesion between PSF polymer and PAN-CMSs, the low volume fraction of carbon in the bulk PSF caused the particles to be surrounded by dense rigidified polymer material. As a result, the functionality of the carbon phase became insignificant. A considerable improvement in $\mathrm{O}_{2} /$ $\mathrm{N}_{2}$ selectivity using the membrane film with 20 wt $\%$ carbon loading was most probably proved the functionality of PAN-CMSs in the membrane film. Consistent with the result obtained in this study, Vu et al. [17] also achieved a significant enhancement in selectivity for both $\mathrm{CO}_{2} / \mathrm{CH}_{4}$ and $\mathrm{O}_{2} / \mathrm{N}_{2}$ due to the incorporation of synthesized carbon molecular sieve (CMS) into Matrimid ${ }^{\text {(C) }}$ 5218 matrix. The PAN-based carbon used in this study might possess comparable molecular sieving property with carbon material from other sources of precursors ever reported. In contrast, at higher loading values, void morphology mostly in the form. of channeling governed the gas flow mechanism. That is why we observed a decrease in selectivity along with dramatic increase in permeability. The 


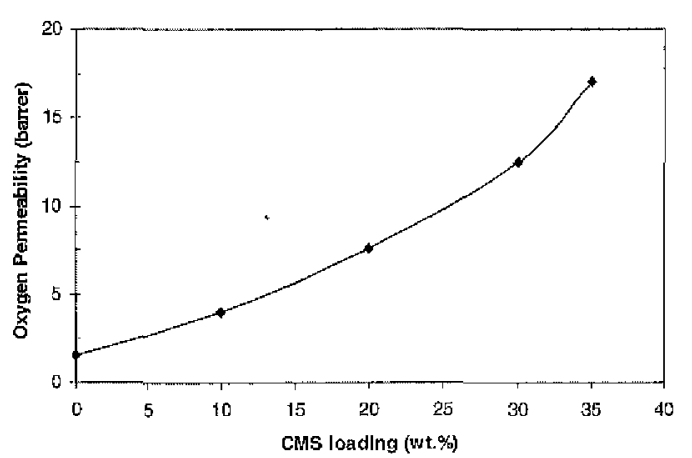

Figure $4 \quad \mathrm{O}_{2}$ permeability for PSF/PAN-CMS $\mathrm{MMM}$ at various PAN-CMS loadings

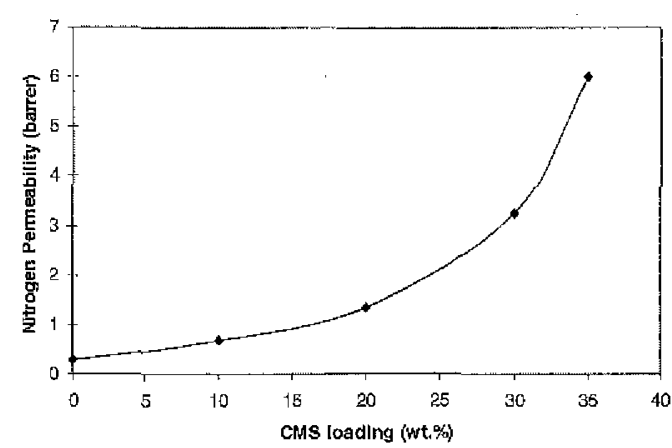

Figure $5 \quad \mathrm{~N}_{2}$ permeability for PSF/PAN-CMS MMS at various PAN-CMS loadings

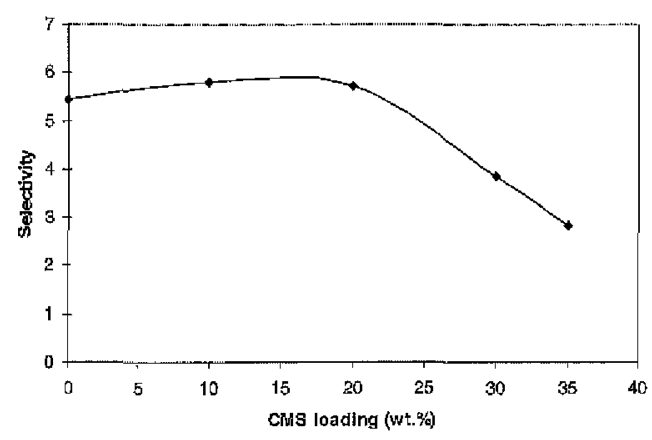

Figure $6 \quad \mathrm{O}_{2} / \mathrm{N}_{2}$ selectivity for PSF/PAN-CMS MMM at various PAN-CMS loadings

rapid increment in both $\mathrm{O}_{2}$ and $\mathrm{N}_{2}$ permeability along with a declining trend in $\mathrm{O}_{2} / \mathrm{N}_{2}$ selectivity as observed in MMM with high carbon loading $(30-35 \mathrm{wt} \%$ ) indicated a high contribution of non-selective passage of penetrants through $1 \mu$ scaled gaps between the PAN-CMSs and the PSF wall or voids within the carbon clusters. These defects could be easily observed in FESEM images presented in Figure 3 (d) and (e). The gas transport through this channel is dominated by Knudsen diffusion mechanism [28]. Since the gas separation via Knudsen diffusion mechanism favors smaller molecular weight penetrant [32], $\mathrm{N}_{2}$ permeated at a greater rate than $\mathrm{O}_{2}$ which in turn severely affected the effective $\mathrm{O}_{2} / \mathrm{N}_{2}$ selectivity. A great loss in selectivity due to formation of non-selective passage or voids at high sieves loading was also reported and discussed in $[17,22,28,29,31]$.

\subsection{CONCLUSIONS}

The potential use of PAN-based carbon for gas separation application can be developed by incorporating the PAN-CMSs into a suitable polymer binder like PSF to form a hybrid material. This study revealed that PAN-CMSs could promote the thermal property of PSF in the hybrid system by extending the glass transition temperature, $T_{g}$ and the decomposition temperature, $T_{d}$. As a result the hybrid of PSF and PAN-CMSs could improve its thermal stability to a greater extent. FESEM micrographs revealed that the hybrid of PSF/PAN-CMSs possess moderate PSF and CMS interfacial adhesion with the average interfacial gap size of less than 1im. These structure allows a better functionality of carbon phase within the MMM. The gas separation capability of PANCMSs were proven as the hybrid film with 20 wt $\%$ carbon loading exhibited higher $\mathrm{O}_{2} / \mathrm{N}_{2}$ selectivity (5.97) than that of pure PSF film (5.50). However, a better separation performance is likely to be obtained by treating the PAN-CMSs or modifying the surface of the PAN-CMSs prior to embedment into polymer binder.

\section{ACKNOWLEDGEMENTS}

The author would like to express sincere gratitude to National Science Fellowship (NSF) from Ministry of Science, Technology and Environment of Malaysia (MOSTE) for the financial support. 


\section{REFERENCES}

[1] A. Gupta, I. R. Harrison. 1996. New Aspects in the Oxidative Stabilization of PAN-based Carbon Fiber. Carbon. 34: 1427.

[2] J. B. Donnet, R. C. Bansal. 1984. Carbon Fiber. New York: Marcel Dekker.

[3] S. M. Saufi, A. F. Ismail. 2002. Development and Characterization of Polyacrylonitrile (PAN) based Carbon Hollow Fiber Membrane, Songklanakarin. J. Sci. Tech. 24: 843.

[4] E. Schindler, F. Maier. 1990. Manufacture of Porous Carbon Membrane. US Patent. 4919860.

[5] V. M. Linkov, R. D. Sanderson, E. P. Jacobs. 1994. Highly Asymmetrical Carbon Membranes. J. Membr. Sci. 95: 93.

[6] V. M. Linkov, R. D. Sanderson, E. P. Jacobs. 1994. Carbon Membranes from Precursors Containing Low-carbon Residual Polymers. Polymer Inter. 35: 239.

[7] S. P. J. Smith, V. M. Linkov, R. D. Sanderson, L. F. Petrik, C. T. O'Cornor, K. Keiser. 1995. Preparation of Hollow Fiber Composite Carbon-zeolite Membranes, Micro. Mat. 4: 385.

[8] V. M. Linkov, R. D. Sanderson, B. A. Rychkov. 1994. Matter Lett. 20: 43.

[9] V. M. Linkov, L. P. Bobrova, S. V. Tomifeev, R. D. Sanderson. 1995. Composite Membrane from Perfluoro-sulfonated Ionomer on Carbon and Ceramic Supports. Mater. Letter. 24: 147.

[10] L. I. B David, A. F. Ismail. 2003. Influence of the Thermostabilization Process and Soak Time during Pyrolysis Process on the Polyacrylonitrile Carbon Membranes for $\mathrm{O}_{2} / \mathrm{N}_{2}$ Separation.J. Membr. Sci. 213: 285.

[11] S. M. Saufi. 2004. Formation and Characterization of Polyacrylonitrile (PAN) Carbon Hollow Fiber Membranes for Gas Separation. Universiti Telnnologi Malaysia. Master Thesis.

[12] H. Yoneyama, Y. Nishihara. 1990. Porous Hollow Carbon Fiber Film and Method of Manufacturing the Same. EP Patent 0394449.

[13] H. Yoneyama, Y. Nishihara. 1992. Carbon based Porous Hollow Fiber Membrane and Method for Producing the Same. US Patent 5089135.

[14] L. Y. Jiang, , T. S. Chung, S. Kulprathipanja. 2006. An Investigation to Revitalize the Separation Performance of Hollow Fibers with a Thin Mixed Matrix Composite Skin for Gas Separation. J. Membr. Sci. 276: 113.

[15] R. Mahajan, W.J. Koros. 1999. Mixed Matrix Membrane: Important and Challenging! Membr. Tech. 105.

[16] C. M. Zimmerman, A. Singh, W. J. Koros. 1997. Tailoring Mixed Matrix Composite Membranes for Gas Separations. J. Membr. Sci. 137: 145.

[17] D. Q. Vu, W. J. Koros, S. J. Miller. 2003. Mixed Matrix Membranes using Carbon Molecular Sieves: I. Preparation and Experimental Results. J. Membr. Sci. 211: 311.

[18] S. Kulpratipanja. 2002. Mixed Matrix Membrane Development. Membr. Techn. 144: 9.

[19] Y. Li, T. S. Chung, C. Cao, S. Kulpratipanja. 2005. The Effects of Polymer Chain Rigidification, Zeolite Pore Size and Pore Blockage on Polyethersulfone (pes)-zeolite a Mixed Matrix Membranes. J. Membr. Sci. 260: 45 .

[20] Y. Li, H. M. Guan, T. S. Chung, S. Kulpratipanja. 2006. Effects of Novel Silane Modification of Zeolite Surface on Polymer Chain Rigidification and Partial Pore Blockage in Polyethersulfone (PES)zeolite a Mixed Matrix Membranes. J. Membr. Sci. 275: 17.

[21] Y. Li, T. S. Chung, Z. Zhuang, S. Kulpratipanja. 2006. Dual-layer Polyethersulfone (PES)/BTDA-TDI/MDI co-polyimide (P84) Hollow Fiber Membranes with Submicron Pes-zeolite Beta Mixed Matrix Dense-selective Layer for Gas Separation. J. Membr. Sci. 277: 28.

[22] R. Mahajan. 2000. Formation, Characterization, and Modeling of Mixed Matrix Membrane Materials. University of Texas at Austin. PhD Dissertation.

[23] T. S. Chung, S. S. Chan, R. Wang, Z. Lu, C. 
He. 2003. Characterization of Permeability and Sorption in Matrimid/C60 Mixed Matrix Membranes. J. Membr. Sci. 21: 91.

[24] A. F. Ismail, P. Y. Lai. 2003. Effects of Phase Inversion and Rheological Factors on Formation of Defect-Free and UltrathinSkinned Asymmetric Polysulfone Membranes for Gas Separation. Sep. Purif. Technol. 33(2): 127-143.

[25] D. Q. Vu. 2001. Formation and Characterization of Asymmetric Carbon Molecular Sieve and Mixed Matrix Membranes for Natural Gas Purification. The University of Texas at Austin. Ph.D Dissertation.

[26] R. Mahajan, W. J. Koros. 2000. Factors Controlling Successful Formation of Mixed Matrix Gas Separation Materials. Ind. Eng. Chem. Res. 39: 2692.
[27] R. Mahajan, W. J. Koros. 2000. Factors Controlling Successful Formation of Mixed Matrix Gas Separation Materials. Ind. Eng. Chem. Res. 39: 2692.

[28] R. Kiyono, G. H. Koops, M. Wessling, H. Strathmann. 2004. Mixed Matrix Microporous Hollow Fibers with Ionexchange Functionality. J. Membr. Sci.231: 109.

[29] P. Hacarlioglu, L. Toppare, L. Yilmaz. 2003. Polycarbonate-polypyrrole Mixed Matrix Gas Separation Membranes. J. Membr. Sci. 225: 51 .

[30] T. W. Pechar, M. Tsapatsis, E. Marand, R. Davis. 2002. Preparation and Characterization of Glassy Fluorinated Polyimide Zeolite-mixed Matrix Membrane. Desalination 146: 3. 